\title{
DIFFUSE B-CELL NON HODGKIN'S LYMPHOMA OF PALATE: A CASE REPORT
}

Manish Kumar Sachan ${ }^{1}$, A. K. Jain², Freni J. K³, Kavish Jhawar ${ }^{4}$

\section{HOW TO CITE THIS ARTICLE:}

Manish Kumar Sachan, A. K. Jain, Freni J. K. Kavish Jhawar, "Diffuse B-Cell NonHodgkin's Lymphoma of Palate: A Case Report". Journal of Evolution of Medical and Dental Sciences 2014; Vol. 3, Issue 25, June 23;

Page: 6896-6899, DOI: 10.14260/jemds/2014/2835

ABSTRACT: Non Hodgkin's lymphoma usually involve lympnodes but can also involve extranodal sites. Oral lymphomas are relatively rare and often difficult to diagnose in a clinical setting. We present a case of a patient of non-hodgkin's lymphoma of the hard palate who had undergone external beam radiation therapy.

KEYWORDS: Lymphoma, Non-Hodgkin; Hard Palate; Maxillary sinus.

INTRODUCTION: Lymphomas are malignant neoplasms of the lymphocyte cell lines. They are mainly classified as either Hodgkin's or Non-Hodgkin's lymphoma (NHL). NHL comprises a heterogeneous group of lymphoid neoplasms with a spectrum of behavior ranging from relatively indolent to highly aggressive and potentially fatal ${ }^{1}$. NHL is a heterogeneous group of malignancies characterized by an abnormal clonal proliferation of T cells, B cells or both. The majority of the adult NHLs are of B cell origin $^{2}$. Palatal and nasal lymphomas are rare and the majority of the lymphomas in this region originate from B cells. Since early detection of hard palate tumors is difficult by clinical examination, the vast majority of such tumors are detected after maxillary or sphenoid bone invasion ${ }^{3}$.NonHodgkin's lymphomas are a group of highly diverse malignancies and have a strong tendency to affect organs and tissues that do not ordinarily contain lymphoid cells. The present report showed a case of B cell lymphoma in a 70 year old male patient manifested as a soft tissue mass on the hard palate.

CASE REPORT: A 70 year old male visited to the ENT Department with complaints of painless, slowly growing mass in oral cavity since more than 1year. On examination, there is no swelling or tenderness over face. Intraoral examination revealed a well defined growth over hard palate, measuring $3.5 \times 2.0 \mathrm{cms}$ with central reddish area. The growth was non-tender on palpation, oral hygiene was poor. On general examination, no lymph nodes were palpable. There was positive history of long term tobacco chewing. There was no history of Diabetes or Hypertension or any other systemic illness.

The clinical differential diagnosis included the most common malignancies in the oral cavity such as squamous cell carcinoma (SCC), minor salivary gland tumor and carcinoma of the maxillary sinus.

The patient was routinely investigated. Complete blood counts were within normal limits. Peripheral Blood smears showed normal White blood cell counts and morphology. FNAC showed features of Non Hodgkin's Lymphoma.

Computed Tomography revealed moderate sized heterogenous soft tissue density with bony destruction involving hard palate, right maxillary antrum, nasal cavity and superior alveolar sockets, suggestive of neoplastic etiology.

Punch Biopsy of the lesion was done and tissue was sent for histopathological analysis. Sections revealed Lymphoma cells, replacing the normal architecture of underlying extranodal tissue 


\section{CASE REPORT}

in a diffuse pattern. Lymphoma cells were large with relatively abundant cytoplasm and irregular nuclei and prominent nucleoli.

Immunohistochemically, the tumour cells were positive for pan B cell markers CD $20+, \mathrm{CD}$ 45+. Finally, the diagnosis of Diffuse Large B cell Non Hodgkin's Lymphoma was made.

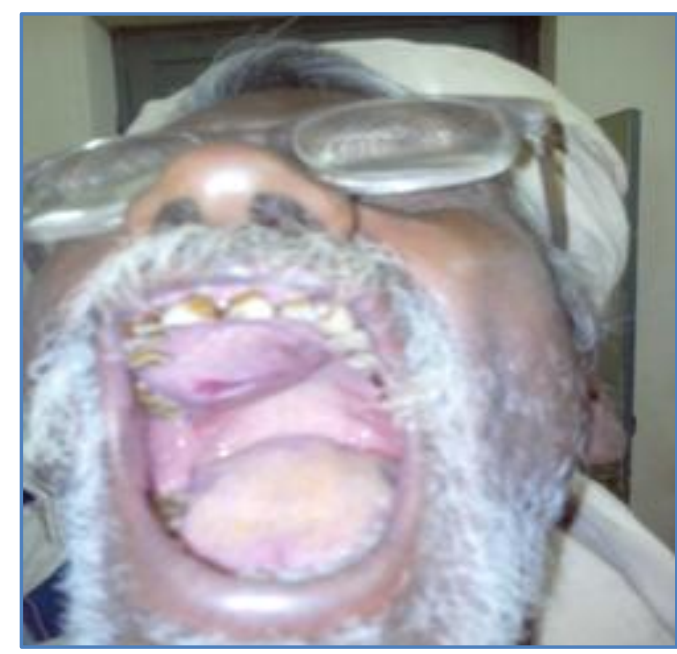

Growth on hard palate

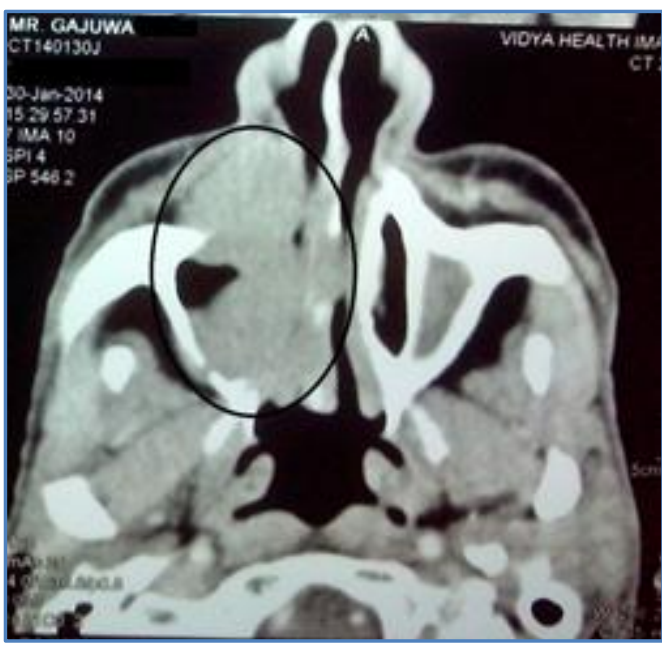

CT Scan showing growth Involving right maxillary sinus

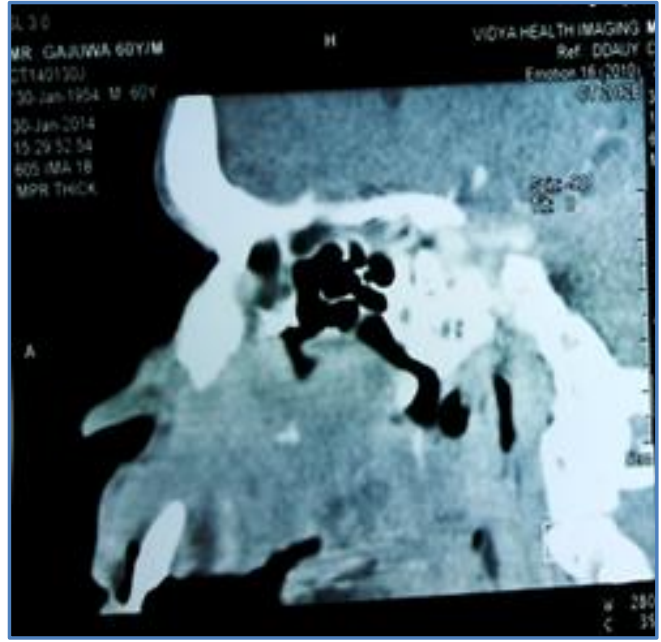

CT Scan sagittal section showing growth involving right maxillary sinus 


\section{CASE REPORT}

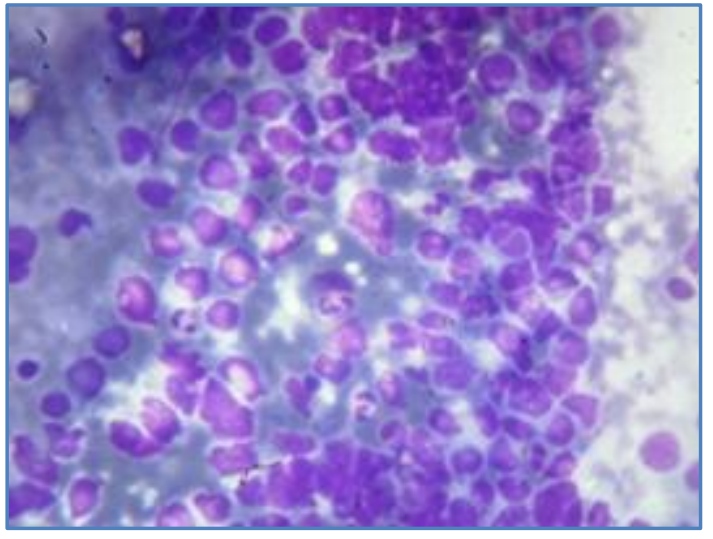

Smear (40X) showing sheet of large Tumour cells normal with scant amount of basophilic cytoplasm

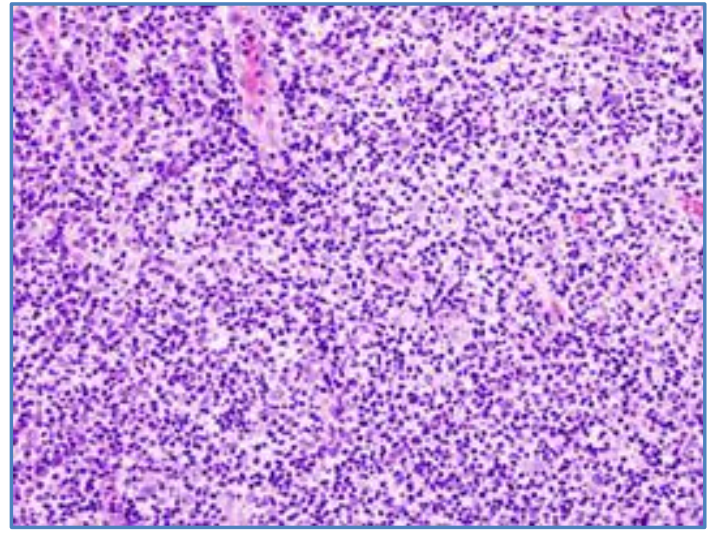

Large cells fully replacing architecture of extranodal tissue

DISCUSSION: Non Hodgkin's Lymphomas are a group of highly diverse malignancies and have a strong tendency to affect organs and tissues that do not ordinarily contain lymphoid cells. The cause of NHL is still unclear. Viruses have been suggested as a potential cause of the disease. Increased rate of lymphoma in patients who are congenitally immunosuppressed and in patients who receive immunosuppressive therapy has been reported.4,6 24-84\% of NHLs arise from extra nodal sites. The head and neck is the second most common site for extra nodal lymphoma after the gastro intestinal tract. 5

NHL is the second most common neoplasm of the head and neck region after SCC and the third most common group of malignant lesions of the oral region after SCC and salivary gland neoplasm. NHL commonly involves oropharyngeal lymphoid tissue comprising Waldeyer's ring, but occasionally involves other oral tissues. Head and neck involvement is generally in paediatric age group, but our patient is 70 year old. Sinuses are the primary site of NHL in $90 \%$ of the cases, most commonly invaded by diffuse large B cell lymphoma. In our case patient had bony destruction in CT scan, which is common in such lesions. Lymphomas are usually submucosal and on gross appearance, differ from SCC which is usually ulceroproliferative, in our case ulceration is absent. Cytological study and biopsy should be performed to ensure accurate diagnosis and histological grading of lymphoma.

\section{REFERENCES:}

1. Salhany KE, Pietra GG. Extranodal lymphoid disorders. Am J Clin Pathol 1993; 99: 472-85.

2. Jayakrishnan R, Thomas G, Kumar A, Nair R. Non-Hodgkin's lymphoma of the hard palate. J Oral Maxillofac Pathol 2008; 12: 85-7.

3. Dalirsani Z, Mohtasham N. T-cell lymphoma of palate with nose and maxillary sinus involvement: a case report. Iran J Med Sci 2010; 35: 254-8.

4. Gedik R, Gedik S, Go"ze F, Develioglu H. Lymphoma in the infraorbital region. IADA 2003; 134: 13535.

5. Teh CS, Chong SY. An unusual presentation of lymphoma of the head and neck region. Med J Malaysia 2011; 66: 264-5. 
6. Lakshmi Kavitha Nadendla, Venkateswarlu Meduri, Geetha Paramkusam. Imaging characteristics of diffuse large cell extra nodal non-Hodgkin's lymphoma involving the palate and maxillary sinus: a case report. Imaging Science in Dentistry 2012; 42: 111-4.

\section{AUTHORS:}

1. Manish Kumar Sachan

2. A. K. Jain

3. Freni J. K.

4. Kavish Jhawar

\section{PARTICULARS OF CONTRIBUTORS:}

1. PG Third Year Student, Department of ENT, Gajra Raja Medical College, Gwalior, M.P.

2. Professor and HOD, Department of ENT, Gajra Raja Medical College, Gwalior, M.P.

3. PG Second Year Student, Department of ENT, Gajra Raja Medical College, Gwalior, M.P.

4. PG Second Year Student, Department of ENT, Gajra Raja Medical College, Gwalior, M.P.

\section{NAME ADDRESS EMAIL ID OF THE CORRESPONDING AUTHOR:}

Dr. A. K. Jain,

Professor and HOD,

Department of ENT,

Ravi Aakriti Bina Complex,

Flat No. G1 and G2,

Gwalior, M.P.

Email: entjainak@hotmail.com

Date of Submission: 09/06/2014.

Date of Peer Review: 10/06/2014.

Date of Acceptance: 16/06/2014.

Date of Publishing: 18/06/2014. 